\title{
EDITORIAL
}

\section{A home for patient-oriented research}

\author{
Kirsten Patrick MB BCh, Maryam Kebbe BSc, Diane Aubin PhD
}

口 Cite as: CMAJ 2018 May 22;190:E607. doi: 10.1503/cmaj.180587

CMAJ Podcasts: author interview at https://soundcloud.com/cmajpodcasts/180587-edit

A Il too often, what's important to patients differs from what health researchers want to study. A recent review in the field of kidney dialysis, for example, showed that only one in five clinical studies addressed an issue that was on a top-10 list prioritized by patients, their caregivers and clinicians. ${ }^{1}$ Researchers were mostly focused on hemodialysis, whereas patients were more concerned with troubling symptoms, such as itching, cramping and restless legs. Patient-oriented research, in which patients play an integral role in the research team, is based on an understanding that people with lived experience of an illness usually have a good idea of what their health care needs are or how they would like to improve their quality of life. It also empowers patients with knowledge and influence while offering researchers greater insight into their area of study. ${ }^{2}$

More than five years ago, the Canadian Institutes of Health Research created its Strategy for Patient-Oriented Research to advance research that "engages patients as partners, focuses on patient-identified priorities and improves patient outcomes."3 The term "patient," in this context, encompasses both patients and their informal caregivers, and engagement refers to collaboration throughout the research process in such areas as priority setting, study design, analysis and knowledge translation.

Patient-oriented research requires a major shift in the way we conduct health research. Some researchers may view the engagement of patients as unnecessary since it adds substantial complexity and expense to health research. There is no clear gold standard yet for how to undertake patient-oriented research; best practice is still being developed, including defining a universally applicable formula for engaging patients. Although there is scarce empirical evidence to show that patient engagement improves clinical outcomes, engaging patients has shown positive impacts, most importantly by increasing the relevance of the research for the patient. ${ }^{4,5}$

If we do not engage patients as active partners in much of health research, we run the risk of wasting public funds to produce findings that are irrelevant to patients or poorly actionable in the real world of clinical practice. Since patients bear the greatest burden of their disease, it is fair and just that they should be key players in establishing research priorities. ${ }^{1}$ We have a moral imperative to ground health research in their unique perspective and experience. ${ }^{4,6}$ Recognizing this ethical duty, many funding organizations now endorse the meaningful engagement of patients in research.

A 2016 editorial in CMAJ declared the journal to be a stakeholder invested in developing patient-oriented research. ${ }^{7}$ Now the CMAJ Group has committed to advancing patient-oriented research by creating a dedicated collection in CMAJ Open for research studies that particularly specify how patients were engaged as part of the research team and how their contributions developed the work. We are guided by a steering committee composed of researchers and patients from across Canada. To foster the inclusion of patient voices, each article considered for the collection will be reviewed by both patient and peer reviewers.

Any emerging field of research takes time to accumulate an evidence base and to build enough collective knowledge to shape methodology. As always, methodologically sound research that is highly novel and clinically important may find a home in CMAJ. However, by creating a dedicated open-access repository for rigorous patient-oriented research in CMAJ Open - a space for promoting its value both in Canada and internationally - we hope to help resolve questions about how best to engage patient partners and evaluate their impact on health research. Ultimately, the goal is to put relevant knowledge that matters into the hands of both patients and health professionals who can use it to improve health outcomes.

\section{References}

1. Jun M, Manns B, Laupacis A, et al. Assessing the extent to which current clinical research is consistent with patient priorities: a scoping review using a case study in patients on or nearing dialysis. Can J Kidney Health Dis 2015;2:35.

2. Brett J, Staniszewska S, Mockford C, et al. Mapping the impact of patient and public involvement on health and social care research: a systematic review. Health Expect 2014;17:637-50.

3. Strategy for Patient-Oriented Research. Ottawa: Canadian Institutes of Health Research; [modified 2017]. Available: www.cihr-irsc.gc.ca/e/41204.html (accessed 2018 Apr. 25).

4. Manafo E, Petermann L, Mason-Lai P, et al. Patient engagement in Canada: a scoping review of the 'how' and 'what' of patient engagement in health research [published erratum in Health Res Policy Syst 2018;16:24]. Health Res Policy Syst 2018;16:5.

5. Domecq JP, Prutsky G, Elraiyah T, et al. Patient engagement in research: a systematic review. BMC Health Serv Res 2014;14:89.

6. Solomon MZ, Gusmano MK, Maschke KJ. The ethical imperative and moral challenges of engaging patients and the public with evidence. Health Aff (Millwood) 2016; 35:583-9.

7. Patrick K. Realizing the vision of patient-relevant clinical research. CMAJ 2016; 188:1063.

Competing interests: See www.cmaj.ca/site/misc/cmaj_staff.xhtml for Kirsten Patrick. No other competing interests were declared.

Affiliations: Deputy editor (Patrick), CMAJ; Department of Pediatrics (Kebbe), Faculty of Medicine \& Dentistry, University of Alberta; School of Public Health (Aubin), University of Alberta, Edmonton, Alta.

Correspondence to: CMAJ editor, cmaj@cmajgroup.ca 